\title{
Enactment and construction of the cognitive niche: toward an ontology of the mind-world connection
}

\author{
Konrad Werner ${ }^{1}$ (D)
}

Received: 4 January 2017 / Accepted: 7 March 2018 / Published online: 15 March 2018

(C) The Author(s) 2018

\begin{abstract}
The paper discusses the concept of the cognitive niche and distinguishes the latter from the metabolic niche. By using these posits I unpack certain ideas that are crucial for the enactivist movement, especially for its original formulation proposed by Varela, Thompson and Rosh. Drawing on the ontology of location, boundaries, and parthood, I argue that enacting the world can be seen as the process of cognitive niche construction. Moreover, it turns out that enactivism-as seen through the lens of the conceptual framework proposed in the paper-considers cognition as a kind of connection between the subject and the world. This post is pointed to as the key idea laid down in enactivism.
\end{abstract}

Keywords Niche $\cdot$ Cognitive niche $\cdot$ Niche construction $\cdot$ Enactivism · Varela • Location · Cognition · Environment · Applied ontology · Connection, evolution of cognition $\cdot$ Enactment $\cdot$ Sense-making

\footnotetext{
I am deeply grateful to Achille C. Varzi for his inspiration, insightful remarks, and encouragement, and to Colin Allen for his most kind hospitality, many discussions, and for making it possible for me to present my work at the Department of History and Philosophy of Science and Medicine, Indiana University Bloomington (thanks to all those who attended my talk, too). My visit to Bloomington also would not have been possible without the support of Joanna Nizynska, head of the Polish Studies Center at IU Bloomington. I would also like to thank Fred Cummins, Peter Godfrey-Smith, and the anonymous reviewers of my paper. This study was possible due to the Mobility Plus grant funded by the Ministry of Science and Higher Education, Poland. Completing this work was also supported by the grant UMO-2016/20/S/HS1/00046 provided by the National Science Centre, Poland.
}

Konrad Werner

k.werner2@uw.edu.pl

1 Institute of Philosophy, University of Warsaw, ul. Krakowskie Przedmieście 3, 00-927 Warsaw, Poland 


\section{Introduction}

I shall address the idea of enactment from a standpoint that has not been taken yet, although it seems well-suited to the task, namely the standpoint of ontology of location, boundaries, and parthood. These correlated disciplines address, mostly in formal(onto)logical terms, what it means for an entity $x$ to be located at some place $y$, or to be placed in some other entity $z$; what it means to share location, to be wholly or partially located somewhere; what it means to have and to share a boundary or to be connected, etc.

In their groundbreaking book The Embodied Mind, Francisco Varela, Evan Thompson and Eleonor Rosh (hereafter VTR) write:

(...) cognition is not the representation of a pregiven world by a pregiven mind

but is rather the enactment of the world and a mind on the basis of a history of

the variety of actions that a being in the world performs (Varela et al. 1991: p. 9)

Now, the ontology of boundaries, location, and parthood can contribute to an understanding of enactment, I argue, because it provides conceptual tools to spell out the two crucial ideas articulated by VTR: first of all, the notion of enactment-of-the-world (hereafter "enactment" for the sake of simplicity) and secondly, the accompanying notion of being-in-the-world. The latter is expressed in terms of location in a niche, particularly in a special kind of niche dubbed the "cognitive niche," while the former is characterized as the process of constructing a cognitive niche. Moreover, using this ontology, we can get a clearer account of what it means that a world and a mind are pregiven or not. The distinction refers to the issue of whether these two parties have boundaries as their parts independently of cognition, thus independently of their interaction. In this context, the proposed rendering of the issue seeks to resolve the idealism versus realism controversy frequently raised with respect to enactment (e.g. Taraborelli and Mossio 2008; Pascal and O'Regan 2008) by adhering to the existence of a mind-independent world, yet one which manifests itself and becomes categorized due to the activity of the cognizing subject.

\section{On the significance of enactment}

Enactment is one of the cornerstones of enactivism. The latter is a still emerging and increasingly complex cluster of theories arguing that the mind is not constituted solely by the brain whose neural firings serve as a vehicle for symbolic representation. ${ }^{1}$ Instead, it is constituted by direct interactions with the environment. Hence, cognition

\footnotetext{
1 This is, broadly, the Cartesian model. Admittedly, Cartesian dualism is not the position that gains traction today, however, contemporary representationalism or cognitivism may be regarded by enactivism as a kind of naturalization of Cartesianism as long as the latter insists that cognition is operated solely by the internal machinery of symbolic representations (see Dretske 1995; Ramsey 2007). The ecological turn is rooted, among other things, in Gibson's (1979) ecological theory of direct perception.
} 
is in principle an activity. As such, it must be realized by the living body, by the whole "environmentally plugged-in" (Noë 2009: p. xiii) living creature. ${ }^{2}$

A detailed and faithful description of enactivism is beyond the limits of one paper, therefore I shall not attempt to provide one (see e.g., O'Regan and Noë 2001; Noë 2004, 2009; De Jaegher and Di Paolo 2007; Stewart et al. 2010; Vörös et al. 2016; Rowlands forthcoming; Hutto and Myin 2013, forthcoming). I shall focus solely on the concept of enactment. Here is a brief explanation of why this notion deserves attention.

It is recognized that enactment provides a way out of the deep-seated Cartesian model of mind-world relations, which draws a sharp diving line between the internal domain of mental life and the external world which is supposed to be clean and clear of any intervention of the mental. Yet, at the same time, the concept in question is deemed problematic and even "extravagant" (Hutto and Myin 2013) due to what Pascal and O'Regan (2008) refer to as its "idealistic underpinning." This is because VTR not only target the mind as constituted by interactions with the environment, but also approach the environment as something constituted by the mind.

However, I argue that the alleged "idealistic underpinning" cannot be the case because the quarrel between realism and idealism only makes sense within the Cartesian tradition which finds itself unable to articulate the idea of "co-determination" of the internal and external (see Werner 2015). Meanwhile, VTR's enactment renders such "co-determination" thinkable, thereby making room for a middle ground between the rock of idealism which treats the world as a mere projection of the mind, and hard realism which targets the world, to use Putnam's (1982) fitting formulation, as ready-made whether or not there is a minded creature bringing forth its own domain of salience. VTR are very clear about this point. I shall come back to the issue in $\S 8$.

Hence, I believe that there are two correlated reasons why the concept of enactment deserves attention. Firstly, from the perspective of a philosopher working within the enactivist current, a closer examination of enactment may be beneficial insofar as it might clarify the very cornerstone of the movement's conceptual framework. I am, however, dedicated to making a more general case. Hence, secondly, examining enactment provides a certain template for non-Cartesian conceptualizations of the mind-world relation, making room for articulating the idea of co-determination, which does not necessarily belong to the enactivist movement proper. This in turn might allow us to see the realism-idealism debate in a new light on a more general level.

\footnotetext{
2 In this context some parties within the movement put stress on the life-mind continuity, drawing on the ideas of Maturana and Varela (1980). Note also von Uexküll's (1926) for the seminal idea of Umwelt (see Rowlands 1999; Di Paolo 2005; Chemero 2009; De Jesus 2015; Cummins and De Jesus 2016; Kirchoff 2016). Embodiment has also been brought up in a different context by Lakoff (1990) and Johnson (1990). Putting stress on embodiment strongly opposes the representationalist idea of cognition thought of as an abstract computation which might be carried out by any system appropriately structured, whether or not it is a living system coupled with its surroundings. Enactivism is in this case naturally linked to the ideas of minimal cognition (see e.g. van Duijn et al. 2006; Barron and Kline 2016); to the question of the evolution of cognition (see Burge 2010; Feinberg and Mallatt 2016; Godfrey-Smith 2016a), i.e. to the broad area of inquiry dubbed cognitive biology by Kovác (2000) (see also Fitch 2008), or the biogenic approach by Lyon (2005).
} 


\section{The pivotal notion of environment}

Now, the notion of environment plays a pivotal role when one raises the question of why the ontology of location, parthood and boundaries is supposed to help in the task of understanding enactment. As Thompson and Stapleton put it, "even the simplest organisms regulate their interactions with the world in such a way that they transform the world into a place of salience, meaning, and value - into an environment (...) in the proper biological sense of the term. This transformation of the world into an environment happens through the organism's sense-making activity" (Thompson and Stapleteon 2009: p. 25).

Firstly, "environment" is by definition a locative term. However, the crucial thing is that being environmentally plugged-in, as Noë aptly puts it, does not mean solely occupying a certain portion of physical space. Rather, this peculiar location is all about, to use a nice articulation by Thompson and Stapleton, the "transformation" of physical space "into environment". Interestingly, Richard Lewontin puts this point explicitly from the standpoint of theoretical biology:

There is a confusion between the correct assertion that there is a physical world outside of an organism that would continue to exist in the absence of the species, and the incorrect claim that environments exist without species. The earth will precess on its axis and produce periodic glacial and interglacial ages, volcanoes will erupt, evaporation from oceans will result in rain and snow, independent of any living beings. But glacial streams, volcanic ash deposits, and pools of water are not environments (Lewontin 2000: p. 48).

VTR clearly line up with this way of thinking when they declare that "our cognition is directed toward the world in a certain way: it is directed toward the world as we experience it. For example, we perceive the world to be three-dimensional, macroscopic, colored, etc.; we do not perceive it as composed of subatomic particles" (Varela et al. 1991: p. 52). Hence, as VTR would say, there is a lived world which is a domain of relatively stable objects, events, and processes as recognized by organisms.

Therefore, there is a certain unity or rather a continuity between mind and world, as a result of which a certain domain or realm comes into being: the lived world, more frequently referred to as the environment. And this domain in turn becomes the locus of the mind. Hence, being environmentally plugged-in is about location plus continuity, and what I want to point out is the fact that the conceptual tools originally developed by the ontology of parthood, location, and boundaries are precisely those that enable us to spell out these two critical notions in conjunction. ${ }^{3}$

This gives me a chance to position my proposal against the background of various paradigms of extended mind (Clark and Chalmers 1998; Menary 2010) and cognitive

\footnotetext{
3 Admittedly, the way in which enactivism makes use of the locative vocabulary is quite problematic and merits separate discussion (just compare the quoted idea of the mind's being environmentally plugged-in with the claim that "cognition has no location" made by Di Paolo 2009: p. 19). However, in this paper I would like to address the notion of enactment directly, leaving these intricate issues emerging at the boundary between enactivism and the theory of location for another occasion.
} 
integration (Menary 2007). ${ }^{4}$ The internal-external gulf is also bridged in these insofar as parts of the world are cast in the role of vehicles of cognition alongside the vehicles within the boundaries of the cognitive agent's body. Therefore, the boundaries of the mind are not identical to the boundaries of "skin and skull" (Clark and Chalmers 1998). And, indeed, the term "cognitive niche," which is my central conceptual posit (see also Werner 2017), was recently employed by Clark (2008) to spell out the idea of cognitive extension (see also Bertolotti and Magnani 2017). ${ }^{5}$ Menary's (2007) and Sterelny's (2010) proposals are in a similar vein. One might therefore argue that what these authors propose suffices to achieve the goal formulated above, namely to move beyond the Cartesian dichotomy of internal versus external.

I argue that the mentioned conceptions are not sufficient to achieve this goal, and the reason is their understanding of environment. There is no room here to spell out this understanding in greater detail, but I would like to highlight that Clark, Menary and Sterelny all treat the environment as a pre-given realm, at most rearranged, thus in some points causally dependent on cognition. This is clear when Clark defines cognitive niche construction as "the process by which animals build physical structures that transform problem spaces in ways that aid (or sometimes impede) thinking and reasoning about some target domain or domains" (Clark 2008: p. 62).

Noteworthy, Clark stresses that all animals "act on their environments and, in so doing, alter those environments in ways that may sometimes change the fitness landscape of the animal itself" (ibid.: p. 61), and he admits that the "transmission of knowledge and practices" thought of as niche construction "yields yet another source of potentially selection-impacting feedback" (ibid.: p. 62). But this is all about causal interventions in arrangements of things in the environment. Menary (2007) calls it reciprocal causation. Yet, the things being re-arranged are already there, constituted independently of the said re-arrangement. This is especially clear when Clark brings up the example of a bartender who "inherits an array of differently shaped glassware and cocktail furniture and a practice of serving different drinks in different kinds of glasses. As a result, expert bartenders (...) learn to line up differently shaped glasses in a spatial sequence corresponding to the temporal sequence of drink orders. The problem of remembering which drink to prepare next is thus transformed, as a result of learning within this prestructured niche, into the problem of perceiving the different shapes and associating each shape with a kind of drink" (ibid.).

Hence, Clark conceives of the cognitive niche as a pre-given realm that becomes re-arranged so as to improve cognition and in this sense may serve as a vehicle of cognition alongside the nervous system. Pinker (2010) thinks of it in a similar vein,

\footnotetext{
4 Many scholars regard the idea of extended mind set down by Clark and Chalmers as a part of enactivism, but its relationship with the whole body of the enactivist paradigm can also be deemed problematic (see e.g., Rowlands 2009).

5 The term "cognitive niche" was also used in the field of evolutionary psychology by Pinker (2010) who draws on Tooby and DeVore (1987). However, in their approaches (and in Clark to some extent, too) it was intended to do justice to the alleged uniqueness of the way in which humans exist and act in the world due to their exceptional cognitive capacities, which is not the case here. My intention is exactly the opposite: I believe that by using the concept of a cognitive niche we can remain true to the continuity between humans and other cognizing creatures. Moreover, the idea of a cognitive niche as spelled out by Pinker had no ontological background and wasn't ontologically thought through.
} 
yet without the extended mind part, and targets the cognitive niche as a task-domain facilitating processes of problem-solving.

Although I am by no means opposing Clark and others, my proposal goes beyond reciprocal causation. This is because the conception I am advocating seeks to account for VTR's pivotal claim that there is no pre-given or ready-made environment waiting to be reconstructed, re-arranged, assorted etc. In other words, Clark and others bridge the gap between the mind and the external world by making the latter part of the genuine fabric of the former, but not vice versa. Meanwhile, my aim is not only to couple cognition causally with the environment, but, following VTR, to render it constitutive of the environment without the alleged "idealistic underpinning."

\section{The niche}

The theoretical framework that I am about to set out has the following three ingredients. The first is provided by theories investigating part-whole relations, i.e., by mereology (Leśniewski 1916; Leonard and Goodman 1940; Simons 1987; Kleinschmidt 2014a, b). This is the formal study of e.g., such real-life situations as: the leg is part of the table; the room is part of the apartment; the computer is part of the network (Varzi 2016). The second ingredient comes from the philosophical examination of some topics in topology; in other words, from topological philosophy (Smith 1996; Smith and Varzi 2000; Varzi 2007). This formal pursuit aims, among other things, at providing an account of the idea of a boundary; e.g., the boundary between the table and the book lying on it; the boundary between Europe and Asia; the boundary between the organism and its environment. Finally, the third and central ingredient comes from the ontology of location, i.e., formal investigation of such situations as e.g., the table's being located in the library; the library's being located in New York; the bear's being located in its cave, but also the thought's being located in the mind (Perzanowski 1993; Casati and Varzi 1999; Kleinschmidt 2014a, b).

Someone might insist on first defining the concept of space and only then location. However, the route taken in the literature that I rely on is opposite: location comes first, and the concept of space, thought of as precisely the space of location, is relative to the kind of location at stake here. ${ }^{6}$

Following the literature, I therefore take three relations as primitive: being a part; being a boundary or having a boundary; and finally being located. Now, the formal theories just mentioned unpack these intuitions by suitable assortments of axioms and

\footnotetext{
6 Just think of these two statements: "I'm in New York City today, so I cannot visit the Grand Canyon this afternoon" versus "I'm in New York City, so I can earn at least 13 dollars per hour." In the first case, by saying "I'm in New York City" I am referring to location in physical space and invoking the Big Apple is just a way of informing someone where in space I am today. Meanwhile, in the second case the physical space or geography is irrelevant as I am referring to NYC as an institution characterized by certain acts of legislation. And I am located within the bounds of that institution, so to speak. So, if NYC were moved mysteriously in physical space by a powerful god, say, closer to Arizona, it would render the first statement false, but the second would remain true. The ontology of location is equipped to cover both situations, so it cannot start by assuming a certain understanding of space and, specifically, it cannot rely on a single account of physical space. As such, the ontology of location is broad enough to cover location in the lived world or environment (the priority of the notion of location is especially clear in Perzanowski's 1993 approach).
} 
then investigate their properties and interconnections by proving certain theses. I will skip formalism, as the construction of a strictly formalized ontology is not my purpose here. In the main body of the article, I also forego definitions of certain concepts such as mereological sum, intersection, difference and complement, characterizing them informally in the footnotes, yet assuming that the basic Boolean relations serving as templates for them are known to the reader. Hence, I limit my rendering of the theoretical framework in play to a certain group of concepts which are to be explained informally or at most semi-formally.

I am interested in a special type of location, namely I am dedicated to bringing up the idea of the niche as set forth by Smith and Varzi $(1999,2001)$ and to build up my own posit on this ground.

To begin with, a niche can be characterized as a volume of space, occupied by some living creature, e.g. a bear's cave or a worm's cavity. In theoretical biology this characterization of the niche is associated with Elton (1927). Meantime, as Smith and Varzi (1999) point out, one can put stress not only on places but also on the conditions to be satisfied if a creature is to thrive, or on the relations obtaining between the creature and its surroundings. Lewontin points out that "ecological niche is a technical term universally used to denote the complex of relationships between a particular species and the outside world" (Lewontin 2000: p. 44; see also Lewontin 1983; Laland et al. 1999). The latter concentration has been stressed especially by Hutchinson (1957) who pointed out that if we take into account any two "ecological factors" $x_{1}, x_{2}$ relevant to a given organism $y$, e.g. temperature and a certain amount of water, then measure them first along the standard Cartesian coordinates, and finally define some limit values for these factors, we obtain a delineated "space" within a system of coordinates. This "space" is an abstract characterization of the niche required by the organism in question, or at least of a part of it. Now, if we take all ecological factors $x_{1}, \ldots, x_{\mathrm{n}}$ that are relevant to the organism, thereby adding new dimensions to the system of coordinates, completing this job would mean that an " $n$-dimensional hypervolume is defined, every point in which corresponds to a state of the environment" (Hutchinson 1957: p. 416) which permits $y$ to exist. This hypervolume Hutchinson calls the fundamental niche of $y$. It is thus clear that the niche, as approached by a scientist of course, not by an animal, should be regarded not so much as a particular place, but rather as an abstract structure which serves as a theoretical postulate by means of which certain things and processes in the world are delineated. Yet, this does not mean that there are no niches in the world. Smith and Varzi (1999) arrive here at two more technical characterizations of the niche: a niche token is a fragment of the world. On the other hand, a niche type is not individuated by its address but by certain conditions to be satisfied. Smith and Varzi show that these two characterizations are complementary. This is because the conditions mentioned have to be realized in some place, thus they always need to be instantiated by a niche token. Therefore, this paper aims to explain how certain niche-tokens are constructed by organisms, yet due to the mentioned correspondence between niche-tokens and niche-types, an ontological enterprise can approach the former via the latter, thus by focusing on characterizing the conditions at stake.

Keeping Hutchinson's abstract approach in mind is crucial as it makes room for different kinds of niches defined by different sorts of conditions not necessarily limited to strictly physicochemical and biological contexts. Therefore, by stressing the 
conditions we can carry on trying to employ the very idea of niche at the most abstract, i.e., the ontological level of thinking. ${ }^{7}$

So here is the leading intuition which is about to be unpacked:

1. A niche is a container. A niched entity is called a tenant.

In order to unpack containment we need two simpler notions as well as the primitive notions of part and boundary:

2. An interior of $x$ is $x$ minus its boundaries; it is, so to speak, $x$ striped from its boundaries. $^{8}$

3. The location of $x$ is the region (address) at which $x$ is located.

So, we have:

4. $x$ is contained in $y$ iff $y$ has a boundary ${ }^{9}$ and the location of $x$ is a part of the interior of the location of $y$.

The niche comes in as a special container. Therefore, the niche is defined by its external boundaries, i.e., boundaries between the interior of the niche and the rest of the world. It may also have internal boundaries which can be dubbed surfaces, i.e., boundaries between the interior of the niche and its tenant (surfaces can be described as ways in which a niche presents itself to its own tenant). Think of these examples of containment: a tool is in the toolbox; a toy is hidden in the box; I am in the building; but also: a book is wrapped in the paper; the snail is hidden in its shell. Here I want only to do justice to the simplest cases, whereas containment as such poses a challenge to any theory of location (see Casati and Varzi 1999, Chapter 8; also Herskovits 1986).

However, the concept of containment unpacks the passive and purely structural aspect of the niche-tenant bond. We need to outline active and functional aspects, too, as they will provide a usable characterization of niche boundaries:

Firstly:

5. A niche is the product of a niche construction activity undertaken by the tenant.

\footnotetext{
7 This is the point at which theoretical biology overlaps with formal ontology (yet, interestingly, the former hardly refers to the latter, see Laland et al. 1999; Laland and Sterelny 2006; Sterelny 2007; Abrams 2009). It is worth stressing, following Smith and Varzi (1999), that the niche, when approached from the ontological - thus the most abstract-point of view, does not have to be associated only with strictly biological contexts. One can consider institutions, cities or states as certain kinds of niches, i.e., as spaces providing people with resources and safety thereby enabling them to thrive by realizing certain aspects of their existence. It is also worth noting that a niche construction theory exists in social science (see Ryan et al. 2016; Wallach 2016).

8 In order to define these notions properly we would need mereological fusion. It can be said that the object $x$ fuses all the objects satisfying the condition A iff each of the objects satisfying A is a part of $x$, and $x$ has no part disjoint from each of the objects satisfying A (this formulation paraphrases the one of Kleinschmidt 2014a). Now, a sum of $x$ and $y$ is the fusion of such $z$ s that $z$ is a part of $x$ or $z$ is a part of $y$. A difference $x$ minus $y$ is the fusion of such $z$ s that $z$ is a part of $x$ and $z$ is not a part of $y$. A complement of $x$ is the fusion of such $z$ s that $\mathrm{z}$ and $x$ do not overlap. To put it simply, it is the domain comprising everything except $x$.

9 It does not have to be bounded all around; think of a glass of wine or an open box.
} 
6. A niche base is thought of as a material ${ }^{10}$ out of which the niche is constructed.

This is likely what Lewontin had in mind when he distinguished environments from the "physical conditions from which environments may be built", and when he stresses that "the actual process of evolution seems best captured by the process of construction" (Lewontin 2000: p. 48), Hence, we have to distinguish between niche construction and the niche as a product. ${ }^{11}$

This topic hints at an ontologically crucial fact, namely, a niche is a product of certain acts of niche construction and as such it cannot be identified with these acts (or processes). ${ }^{12}$ This is because acts and products bear different properties (see Twardowski 1912/1991). Think of the process of painting and $a$ painting that results from it. One can provide a detailed description of the process of painting, e.g., of the technique used or drugs taken by the artist while only scarcely mentioning what is being painted; on the other hand, we can ponder on the message conveyed by the ready-made painting without any idea of the technique or of the said drugs.

Secondly, being contained in a niche must somehow be significant for the tenant; namely, the niche is a place in which the tenant can thrive. The niche must then provide resources to the tenant. In order to this, the niche must be filled with certain stuff such as e.g., air satisfying certain conditions like temperature, pressure etc.; with certain nutrients; with a certain amount of light; some useful objects; etc. All of these items constitute what is called the medium of the niche.

Now, if we closely examine the notion of medium, it turns out that it is not sufficient for an entity to be merely placed in the niche in order to participate in the medium. Following Smith and Varzi, think of a bat in the bear's niche. It is located there but it is not part of the medium because its presence is irrelevant to the bear's life and needs. So, Smith and Varzi (2001) stress that a medium exists only relative to a given type of organism. At this point, without entering into the details of whether or not living creatures have a genuine goal-directedness (see Weber and Varela 2002; De Jesus 2015; for a more general picture Allen et al. 1998; Godfrey-Smith 2014), we can concede that for all living creatures, including bacteria moving toward attractants and away from repellents (see Di Primio et al. 2000; van Duijn et al. 2006; Cummins and De Jesus 2016), the world consists of some quantity of items that can benefit

\footnotetext{
10 One is tempted to invoke "physical stuff" or "physical reality," as Lewontin did, but there is no need to make this presumption; the key factor is that the stuff in question exists independently of cognition. Calling it "physical" would suggest a physicalist metaphysics which is alien at least to some versions of enactivism, including VTR.

11 Together with the niche construction process we should also bring up and investigate the act of maintaining a niche which is a closely related, yet in some respect different, procedure. I owe this remark to Achille C. Varzi.

12 I draw here on Twardowski's (1912/1991) fundamental distinction between acts and products. The distinction is based on "grammatical analyses, purporting however to show logically salient differences" (Betti 2016), e.g. running and run; judging and judgment; speaking and speech; painting and a painting. For Twardowski and his readers, most importantly for Edmund Husserl, the crucial thing is the distinction between mental processes conveying certain contents and theses contents thought of as products of the aforementioned mental processes; products that - unlike processes - are subjected to logical analysis. Hence, the distinction enabled philosophers to address the threat of so-called psychologism looming on the horizon and-in Twardowski's, Husserl's and Frege's (earlier) understanding — endangering the swift development of logic at the time.
} 
them as well as items that can impair them. In both cases, the items just mentioned are relevant to these creatures, in contrast to things whose occurrence makes no difference (see Godfrey-Smith 1996; Lewontin 2000).

The concept of autonomy, fundamental to the enactivist project, gives us a clue as to how to approach the relevance of a niche or rather that of its medium:

Considered abstractly, for a system to be autonomous, its constituent processes must meet the following conditions:

(a) recursively depend on each other for their generation and their realization as a network;

(b) constitute the system as a unity in whatever domain they exist; and

(c) determine a domain of possible interactions with the world (Thompson and Stapleteon 2009: p. 24; original punctuation changed)

In this context:

7. The relevance of a given entity means that the entity is required by the autonomy of the tenant. This is because "[...] on the basis of its autonomy the system selects or enacts a domain of significance" (Varela et al. 1991: p. 156).

Finally, we can account for the Eltonian understanding of niches as containers in more Hutchinsonian terms, namely in terms of conditions rather than places:

8. A niche is a container whose external boundaries delineate only entities that are relevant to the tenant; i.e., the boundaries are established by a set of conditions that are necessary to maintain the tenant's autonomy. This means that for a given tenant $x$ there are certain things and interactions required by $x$ 's autonomy.

And here are my core claims, binding enactment with the ontology of the niche. Namely, I propose that:

9. Enacting-the-world means constructing a niche from a fixed base.

10. Being-in-the-world means a tenant's being located (contained) in a niche, thought of as a relatively stable product of niche construction activity.

Therefore, in order to account for enactment we have to provide a comprehensive characterization of niche construction. The latter can be characterized provisionally as a transformation of the niche base into the niche medium. And the real puzzle concerns the proper ontology of that transformation.

To begin with, let us take a closer look at the notion of relevance.

\section{The cognitive niche}

Note that for a given creature at a certain level the relevance of a niche's medium has nothing to do with cognition, as for example the relevance of oxygen particles deployed in the bear's niche. Nonetheless it seems that there are also cases in which we would be missing something if we did not invoke cognition. Imagine that suddenly a snail gets into the bear's cave, thus a candidate for food. In this case the snail has to be properly "recognized" by the bear as relevant to its metabolism and certain action must be taken in order to get the snail. The relevance must be mediated by certain cognitive 
factors. On the contrary, the bat living in the very same cave is likely "recognized," yet as irrelevant (at a given moment) to the bear's needs.

The example of the bear given above might suggest that I assume a certain understating of cognition as involving rather complex information processing. ${ }^{13}$ However, I don't, and-crucially-I believe that it would not be good to define "cognition" upfront. Nonetheless, I do agree that we are in need of some kind of working, regulatory idea or, in fact, an heuristic rather than a proper and explicit formulation of what "cognition" generally is. For the purposes of this paper, we need an heuristic that is at least acceptable from the enactivist point of view.

van Duijn et al. (2006) who, strictly speaking, do not enlist themselves for any enactivist party, come up with the idea that will serve as my point of departure: in their view, cognition is a meta-metabolic process of sensorimotor coordination. By "metametabolic" (the term introduced by Moreno et al. 1997) they mean a process that is not part of metabolism, yet one that metabolism benefits from. Of course, full comprehension of what this means requires a more elaborate discussion of metabolism itself. For now, let me rely on the apt characterization provided by Godfrey-Smith (2016a) according to which metabolism is a group of processes that maintain and rebuild organisms, enabling them to grow, develop, and reproduce. In this context, van Duijn et al. (2006) argue that e.g. the chemotaxis of E-coli, i.e., the ability to stop tumbling and to move towards an attractant or escape from a repellent, is not metabolic in the strict sense, thus it cannot be explained merely by reference to chemical interactions providing energy for a bacteria to maintain their unity and thus to thrive. There is something more that is needed, they argue, meaning "physical changes in the position of the bacterium with respect to its environment. In other words, the environment is manipulated at a larger, physical level" (van Duijn et al. 2006: p. 164).

I believe that the idea of meta-metabolism crucially contributes to our understanding of cognition by targeting the latter as a meta-metabolic capacity of pursuing sensorimotor coordination. ${ }^{14}$ There is, however, one more feature of cognition that is crucial to VTR and not so clearly articulated in the idea of meta-metabolism itself. Namely, cognition is supposed to be productive, meaning that it brings forth a certain domain or realm: the environment or the lived world, as it is referenced by VTR and their phenomenological predecessors (most importantly Maurice Merleau-Ponty). Now, I argue that the contribution of niche ontology is non-trivial as long as it can account for how these regulatory and coordinative-sensorimotor processes mentioned by van Duijn et al. (2006), but also by Hutto and Myin (2013), are productive, i.e., how they bring forth the lived world.

Eventually, the working idea of cognition that I employ for the purposes of this study is the following: cognition is a productive, meta-metabolic capacity of sensorimotor coordination.

\footnotetext{
13 I would like to thank the anonymous reviewers of this paper for singling out and highlighting this issue.

14 By drawing on van Duijn et al (2006) my intention is not to make the case that cognition in all its instantiations is nothing more than sensorimotor coordination performed by such creatures as E-coli. My intention is merely to formulate a baseline working idea of cognition for the purposes of this particular study. I am also aware that there is a controversy over whether cognition can be identified with behavior, but here I prefer to bind cognition with behavior without taking this more controversial step; see e.g., Aizawa (2015).
} 
However, it is worth explaining why this is only a working idea and not a proper definition. So, firstly, the ontological framework unpacked here is not suited to any specific theory within the sciences: it is an unsaturated structure, as it were, that is open to many saturations. The only thing I rely on is that some distinctions between biological functioning and cognitive functioning are drawn by specialists in different fields and play explanatory roles. For example, Moreno et al. (1997) hold that in order to be truly "decoupled" from metabolism, a process must be realized by a developed nervous system, thus in their view the meta-metabolic processes and functions emerge at a much "higher" level in the evolution of complexity. Now, without lining up with van Duijn et al. (2006) or Moreno et al. (1997) as to when the first cognitive acts emerged, my approach remains in keeping with the general conviction that it makes sense to draw a line-somewhere-between the metabolic proper and the cognitive.

Secondly, cognition can hardly be strictly defined not only because there are theories within the cognitive sciences that address cognition on so many different levels, from humans, through other complex animals, down to unicellular organisms, but-take it as a straightforward de re argument-because there are all these different ways in which cognition can be realized, and thus the distinction between the cognitive and the non-cognitive or pre-cognitive does look different when it comes to E-coli (if it is applicable to them at all) and when it comes to octopuses (see Godfrey-Smith 2016 b), not to mention humans. Hence, I share to some extent the skepticism regarding philosophical attempts to pin down the "mark of the cognitive," to draw a clear dividing line between cognition and non-cognitive phenomena, as most recently expressed by Allen (2017; see also Aizawa 2015; Akagi 2017).

Now, keeping in mind the working account of cognition proposed above, I propose that autonomy sets up the two kinds of relevance, thus the two arrangements of conditions: the metabolic in the strict sense, thus having to do with the organism's maintenance of its own unity, let's dub them conditions $M$, and the cognitive, having to do with the organism's (meta-metabolic) interactions, let's dub them conditions $C$. Hence, alongside many possible factors serving as the conditions for a niche, understood in the Hutchinsonian, abstract way, there are the conditions $C$, that determine for a given creature what is cognitively accessible to it; in other words - taking into account the working account of cognition accepted above-conditions $C$ determine for a given creature what meta-metabolic, sensorimototor activities the creature is capable of.

Hence, a rough distinction can be made between a metabolic niche (M-niche from now on), i.e., one that provides a secured space and resources for metabolism and picks up only those entities from the niche base that satisfy the conditions $M$, i.e., are relevant to metabolism, and what I would like to call the cognitive niche (C-niche), i.e., one that contains only those entities that satisfy the conditions $C$.

11. The metabolic niche (M-niche) of $x$ is a niche whose external boundaries are set up by the conditions $M$;

12. The cognitive niche (C-niche) of $x$ is a niche whose external boundaries are set up by the conditions $C$ (provided the provisional characterization of cognition given above). 
To get a sense of what is at stake, think of the following setting: suppose we have a creature $x$ whose only sense is hearing and whose sense organ is sensitive to sound waves between $15 \mathrm{~Hz}$ and $20 \mathrm{kHz}$. Now, $x$ is surrounded by $a, b, c$. Suppose that $a$ is relevant to $x$ 's metabolism and $a$ 's vibrations produce waves with a frequency of around $50 \mathrm{~Hz} ; b$ is irrelevant to $x$ 's metabolism and the frequency of its vibration is $17 \mathrm{kHz}$; finally $c$ is also relevant and it vibrates with the frequency of $70 \mathrm{kHz}$. If this is the case, $a$ and $b$ belong to the base of $x$ 's C-niche, despite the fact that $b$ does not belong to the base of $x$ 's M-niche. On the other hand, $c$ does not belong to the base of $x$ 's C-niche despite the fact that it belongs to the base of $x$ 's M-niche. Finally, we can see that $a$ belongs to the bases of $x$ 's M- and C-niches.

Here is a more real-life depiction, drawing on the already cited examples of the bear, the bat, the snail, and the air: the snail belongs to the base of the bear's C-niche as well as to the base of its M-niche as a "recognized" candidate for food, while the bat belongs to the former (since it is likely "recognized" by the bear), but not to the latter. The air, on the other hand, belongs to the base of the bear's M-niche, but not to the base of its C-niche, since bears (unlike humans living in smoggy cities) most likely do not "problematize" the presence of air. This setting is simplified, as it neglects the fact that at the end of the day we don't know what it is like to be a bear, a snail, not to mention a bat, and how these creatures perceive each other (instead of saying that the snail belongs to the base of the bear's C-niche or M-niche, I should have said that what we call a snail belongs there). Nonetheless, this can at least give us some initial sense of how C-niches and M-niches can differ when it comes to their contents. ${ }^{15}$

\section{Niche construction and connection}

Now, VTR give a clear suggestion as to what the transformation of the niche base into the niche medium means, at least when it comes to cognition; thus, when it comes to C-niches. They write:

The tacit assumption behind the varieties of cognitive realism (...) has been that the world can be divided into regions of discrete elements and tasks. Cognition consists in problem solving, which must, if it is to be successful, respect the elements, properties, and relations within these pregiven regions (Varela et al.: p. 147)

When opposing cognitivism, VTR argue, one has to oppose the view that there are regions in the lived world independently of cognition. Therefore, "when we enlarge the task domains from artificial microworlds to the world at large, it is not clear that we can even specify what is to count as an object independent of the type of action that is being performed. The individuation of objects, properties, and events appears to vary according to the task at hand" (ibid.: p. 148; my highlights).

\footnotetext{
15 Let me note that Smith and Varzi (1999) unambiguously alluded to the idea of cognitive niche when they referred to Gibson's (1979) theory of surface as well as to von Uexküll's (1926) notion of Umwelt. Moreover, Lewontin stressed that there is, in my reading, a cognitive aspect in each niche because "organisms determine which elements of the external world are put together to make their environments and what the relations are among the elements that are relevant to them" (Lewontin 2000: p. 51).
} 
Hence, VTR's first suggestion is that the said transformation is not about a subject mirroring the structure of an external world and adjusting to it. While such mirroring presupposes a certain distance between the two pre-given realms - the subject and the external world-VTR hint at the possibility of a closer tie, perhaps a continuity between the subject and its environment. The second suggestion is about boundaries: VTR seem to claim that the world consists of no ready-made divisions or cut-offs between objects, events, properties, etc.-thus no boundaries-unless it is cognized. Therefore, the transformation of niche base into niche medium must have to do with these boundaries coming into being.

This is the point where, in my reading, the most groundbreaking posit of VTR is unveiled: cognition is not about representing the existing boundaries or surfaces of the surrounding world but about establishing boundaries within it, so that the world shows itself (is brought into presentation, as Edmund Husserl would say) in the guise of a C-niche as divided into regions and objects, in accordance with the cognizer's autonomy. And this is not about creating representations of boundaries; it is about bringing them forth in the world.

Note in this context that one of enactivism's goals is to free us from the fixation on human cognition, thus - among other things - from the fixation on vision. The latter makes the ideas of mind-world continuity and cognition as establishing boundaries in the world seemingly outlandish. On the contrary, for example, Noë (2004) wants to convince us that all perceiving is like a blind person's tap-tapping. This illustration, if I understand correctly, is supposed to convey the message that perception establishes a closer tie between the cognizer and the environment than the fixation on vision would suggest. Tap-tapping is, however, mere abutting, meaning that there are two separate things whose boundaries are so close in space that they seem to overlap, yet there is no connection between them. Meanwhile Hutto and Myin's (2013) commitment to minimal cognizers, shared by many other proponents of enactivism, suggests something even more revolutionary. Think of the paradigmatic case of bacterial chemotaxis, aptly dubbed the myth of an enactive cell by Cummins and de Jesus (2016). If the mythical cell is able to sense a given attractant or a given repellent in the medium and to adopt a certain mode of action with respect to that "perception," this must involve a chemical reaction as result of which some portion of the medium must - to put it roughly—react with some part of the cell (on its boundary, i.e., membrane) and mix up in such a way as to produce a reaction of the whole cell. If the category of cognition makes any sense at this level—which is the subject-matter of controversy-cognizing is surely not mere abutting one another, as there is a clear continuity between the medium and the membrane. ${ }^{16}$

Going back to humans, instead of fixating on vision, just think of our own chemical senses. It makes perfect sense to say that I learned about the taste of shrimps once I took a bite, meaning that the gustatory perception was a source of knowledge or

\footnotetext{
16 When making this speculative point and bringing up the case of the mythical E-coli (and, subsequently, our own sense of taste), I have assumed that chemical reactions could be unpacked mereologically as cases of sharing parts, i.e. overlapping, which may seem controversial. Mereology of chemistry, to my knowledge, has not been employed in analyses of cognition so far, nonetheless, it has been addressed on its own, and we are not left short of literature on this subject. Here I follow the study of Llored and Harré (2014).
} 
information, not just energy for my metabolism. Yet, it is clear that this perception was grounded, as in case of $E$-coli, in chemical reactions going far beyond mere abutting of surfaces. ${ }^{17}$

Think of hearing. If we just bracket our vision-based notions of a bird or pebble plunging into a lake, it is not so clear what counts for a creature having only the sense of hearing as an object, and what/where are its boundaries. It is by no means obvious that the boundaries of the bird as it is heard or the pebble as it is heard are identical to the boundaries of the bird as it is seen and the pebble as it is seen. ${ }^{18}$ And even making a comparison is problematic, as it may be the case that these two sets of boundaries are set up by entirely different sets of conditions, the one established with respect to the boundary and functioning of the visual system, and the other somehow with respect to the boundary and functioning of the auditory system, both tied to certain patterns of action.

Someone might argue at this point that the specification of boundaries invoked by VTR does not have to mean establishing boundaries or surfaces. They could simply be there, whereas specification works as a kind of selection of surfaces. VTR's answer is, however, as straightforward as can be:

But how are we to specify what counts as a surface? How are we to specify its edges, boundaries, texture, and orientation, if not in relation to some perceiver for whom these distinctions are relevant? (ibid.: p. 167)

They are thus unequivocally clear about what this means for cognitive science:

If, however, our lived world does not have predefined boundaries, then it seems unrealistic to expect to capture commonsense understanding in the form of a representation - where representation is understood in its strong sense as the re-presentation of a pregiven world. (ibid.: p. 148)

If VTR's claims are generalized so as to apply to both kinds of niches, then perhaps they can tell us something about niche construction as such. Let us take this path stepwise.

Firstly, I introduce, following Smith and Varzi (1999), the formal notions of overlap and connection:

13. Two objects $x$ and $y$ overlap iff they have a common part. If $x$ and $y$ do not overlap, they are disjoint.

14. Two objects $x$ and $y$ are connected iff $x$ and $y$ overlap or the closure of $x$ overlaps with $y$ or $x$ overlaps with the closure of $y$.

And the notion of closure is understood in the following way:

15. A closure of $x$ is the sum of $x$ and its boundaries.

\footnotetext{
17 Interestingly, Johnston (2006) once proposed (in a different context) that perception is like digestion. Yet, this comparison was explicitly rejected by Noë (2009) who, apparently, did not recognize its, say, enactivist potential.

18 Volkenburg and Kubovy (2001) introduced the notion of auditory object in this context. Speaking of birds on both sides still renders vision privileged when it comes to our imagination, but otherwise the illustration would likely be too abstract to substantiate the point.
} 
This means, roughly, that $x$ and $y$ are connected if they share a part or if they share a boundary (when they are, for instance, "sewn" by a common boundary).

16. Two objects $x$ and $y$ are externally connected iff $x$ and $y$ are connected but they do not overlap. This restricts connection to the case of sharing a "sewing" boundary.

Here comes the pivotal point, made already by Smith and Varzi (1999), which unpacks the said issue of continuity between the subject and its environment:

17. A tenant is connected with its niche.

The concept of the niche-tenant connection refers to a certain relation in the world, not to an activity, so it unpacks the static aspect of the bond in question. However, we can think of its dynamic aspect, too, and this provides a good characterization of the niche construction process:

18. Niche construction consists of setting up connections with relevant parts of the niche base so that they become parts of the niche's medium; setting up connections so that they are incorporated into the realm in which the tenant realizes its autonomy.

Now, in order to get a handle on this newly introduced concept of setting up connections, let us focus on boundaries and on VTR's claim that there are no pre-given boundaries in the world. Two more formal concepts are required to carry on this exposition. Following Smith and Varzi (1999):

19. Object $x$ is open iff $x$ is identical to the interior of $x$; informally $-x$ is open when it has no boundary as its part.

20. Object $x$ is closed iff $x$ is identical to the closure of $x$; informally, $x$ is closed when it has its boundaries as its parts all around, as it were (for simplicity I omit cases of partial openness/closedness).

To get the sense of the open-closed distinction we can visualize an open object (keeping in mind that this is just a depiction) as an aggregate of scattered entities such as a swarm of bees. Meanwhile it is crucial not to imagine boundaries as something similar to wrapping paper, thus as an actually separated or separable entity. The minimal assumption behind topologically-inspired ontology is that we need a notion of boundary to account for the observable continuities and discontinuities between things, while the metaphysical status of boundaries is unresolved at the starting point. It remains to be investigated whether boundaries are bona-fide or fiat, mind-independent or mind-dependent, but certainly it would be outlandish to say that one can strip a cup of coffee of its boundaries and as result end up with the stripped cup in one hand, and the cup's former boundary in the other. Boundaries are certainly not separable in this sense.

Since niches are entities of a special kind, namely containers, and since they play certain functional roles for their tenants, their characterization as open/closed should be adjusted. I therefore propose:

21. If $x$ is a niche, and $y$ is its tenant, $x$ is externally closed iff it has its external boundaries as its parts, which means that the external boundaries of $x$ are determined by the conditions of $y$ 's autonomy. 
22. If $x$ is a niche, and $y$ is its tenant, $x$ is externally open iff it does not have its external boundaries as its parts, which means that the external boundaries of $x$ are not determined by the conditions of $y$ 's autonomy.

As I have already stated, a niche is defined by its external boundaries, so it seems that a niche cannot be open. In reality, of course, things are much more intricate, but for the sake of this simplified theory we can assume that a niche must be externally closed-it belongs to the very essence of any niche that the way it is delineated from the rest of the world hinges on the autonomy of its tenant.

Now, more intriguing puzzles come up as we focus on the internal boundaries of niches and the boundaries of their tenants:

23. If $x$ is a niche and $y$ is its tenant, $x$ is internally open iff it has no internal boundary as its part, which means that the conditions of $y$ 's autonomy do not determine any stable setup of the internal boundaries (surfaces) of $x$.

24. If $x$ is a niche and $y$ is its tenant, $x$ is internally closed iff it has its internal boundaries as its parts, which means that the conditions of $y$ 's autonomy do determine a stable setup of the internal boundaries (surfaces) of $x$.

25. If $x$ is a niche and $y$ is its tenant, $y$ is closed (to $x$ ) iff it has its boundaries as parts, which means that the conditions of $y$ 's autonomy do determine a stable setup of demarcation lines dividing what belongs to $y$ and what belongs to its niche.

26. If $x$ is a niche and $y$ is its tenant, $y$ is open (to $x$ ) iff it has no boundary as a part, which means that the conditions of $y$ 's autonomy do not determine a stable setup of demarcation lines dividing what belongs to $y$ and what belongs to its niche.

By "stable setup" I mean that the boundaries in question must be structures that are more or less robustly maintained. In other words, if we imagine, for example, black and white paints mixed in a bucket, we will likely have something like boundaries in view, separating the two colors before they merge, but such momentary structures, although they may count as boundaries from a purely formal-ontological perspective, are not boundaries in the sense applying to the functioning of such complex structures as organisms and their niches. Deeming such momentary divisions as boundaries would make the category trivial in this context.

In light of the terminology set out above, VTR's belief that there are no pre-given boundaries in the world means, in my reading, that the niche base is open. This gives us a clue as to what it could mean for an organism to construct a niche by setting up connections with entities so that they become parts of its niche's medium. Namely:

27. If $x$ is a niche and $y$ is its tenant, constructing $x$ means that $y$ provides the entities serving as $x$ 's base with boundaries in accordance with the conditions of $y$ 's autonomy. This means that $y$ is closed and $y$ 's boundaries have started to serve as boundaries for the niche base, thereby establishing the internal boundary of the newly constructed niche $x$.

Roughly, in the described case the tenant "lends" its own boundaries so that they start to function as the boundaries (surfaces) of the surrounding entities which have no boundary on their own. As result, the tenant becomes externally connected ("sewn" together) with these entities. 


\section{Patterns of co-determination}

However, one might point out that enactivists invoke the idea of mutual dependence between the cognizer and its environment, not only determination of the latter by the former. For example Hutto and Myin write:

Enactivists hold that these dynamic interactions - in which cognition literally consists-are loopy, not linear. (...) Variables in the environment influence and are influenced by variables in the brain and the non-neural body in a recurrent manner, making it impossible to conceive of these as linear relations holding between inputs and outputs. (...) From the vantage point of dynamical systems theory, there is no way to isolate properly mentality constituting "inner" organismic responses from "outer" ones that allegedly stand over and against the former as mere causal contributions from the environment. On this model, there is no prospect of making any such principled division. (Hutto and Myin 2013: p. 6)

The point made here by Hutto and Myin, when unpacked by means of the proposed terminology, is that not only the boundary of a niche but also the boundary inherent to its tenant emerge over the course of interaction.

This mutual determination (co-determination) is stressed by VTR too, since along with the abandonment of the pre-given world, they also abandon the pre-given cognizer. They write explicitly that "knower and known, mind and world, stand in relation to each other through mutual specification or dependent coordination" (Varela et al. 1991: p. 150; my highlights). If co-determination is the case then in principle neither of the boundaries, either the one ascribed to the niche or the one possessed by its tenant, is fixed upfront.

On the other hand, however, VTR can hardly strip the cognizer of its boundaries, thus render it open, as long as autonomy is at stake. The very idea of autonomy seems to imply some kind of separation. This situation may make one inclined to follow the claim made by Di Paolo (2009) as well as Thompson and Stapleton (2009), that capturing cognition, thought of as enactment or sense-making, in terms of location and boundaries is in principle misguided and should be abandoned. But how is it possible to abandon locative terms and at the same time to keep the notions of environment as well as being-in-the-world which play crucial roles in the enactivist project? I will make another approach by making use of the distinction between M-niche and C-niche.

So, firstly, I assume that if the cognizer and the world are to be regarded as reciprocally co-determined, they have to be deemed open at the initial stage of codetermination, thus before the first step in this process is taken. This does not mean that the two sides are completely mixed; rather, they are indefinite at their extremes. Think of such everyday examples as a mountain, a foot of the mountain and the piedmont - all of these entities surely exist on their own, and thus are neither mixed nor conflated, nor wedded to the mind, but there is no clear dividing line between them and at the end of the day people draw the line for practical purposes. Indeed, when it comes at least to multicellular organisms, it is widely recognized that their boundaries are not clear cut-offs, too (see Godfrey-Smith 2016a; also Menary 2007).

Hence I would like to roughly distinguish several stages of dynamic niche-tenant construction happening over the course of evolution in order to unveil the dynamics of 
co-determination. The initial stage refers to the starting moment, $O$, which is artificially postulated here for the sake of the argument and not intended to single out an actual moment in natural history:

28. At the moment $O$ both the world (future niche base) and the organism (future tenant) are open.

This means, in step with VTR, that in principle the world and the cognizer are not pre-given. Let me now refer to Godfrey-Smith (2016a), who is not an enactivist, yet comes up with a distinction which enables my niche-based reconstruction of codetermination to take off. He distinguishes two functions of the nervous system: the one that is widely appreciated and stressed in enactivism, i.e., coordination of sensory input and behavior; and a more primitive function, namely agent-building, thus the internal coordination of the parts and functions of a complex living creature so that it can behave as a whole. Invoking the Ediakaran fauna and the Cambrian explosion, Godfrey-Smith writes:

Our animal cousins are highly alert to their environment; they track friends, foes, and countless other features of the landscape. They do that because what's going on around them matters; often it's a matter of life and death. Ediacarans lives show no evident sign of this moment-to-moment engagement with the environment. If so, this makes it likely that our Ediacaran ancestors put their nervous systems - when they had them - to different uses from those seen in more recent animals. Specifically, this might have been a time when the role played by those nervous systems fits the second of the theories of nervous system evolution I introduced above, the view based on internal coordination rather than sensory-motor control. (Godfrey-Smith 2016b: pp. 31-32)

In the Cambrian, animals became part of each other's lives in a new way, especially through predation (ibid.: p. 34)

Using this template, yet not necessarily with respect to the nervous system but rather to the whole organism as such, I shall render metabolic niche construction as a process whose purpose is precisely agent-building in Godfrey-Smith's sense; i.e., the production of the organism, so to speak, therefore whose result is the organism's becoming closed (bounded), distinguished from the exterior. And I propose that Mniche construction is the first step in the process of mutual co-determination, resulting in a closed tenant. The purpose of the M-niche is to provide the resources required for metabolism, and therefore it is all about building a closed, stable tenant, but not about building a stable environment (which comes later).

Hence, I propose that:

29. At the first stage of co-determination, M-niche construction produces a certain stable, closed tenant. Hence, the tenant is closed while its M-niche is internally open.

Now, once the first specification of the tenant is completed, and if there arises for the tenant a possibility of undertaking certain actions as a whole, co-determination can go further. We have stable patterns of tenant self-maintenance, but still no stable 
patterns of action or behavior, and therefore no stable environment. The environment at this stage is still an indefinite flux. Of course, certain stuff in the surrounding world matters to the tenant (i.e., stuff composing the medium of the M-niche), yet this is not sufficient, I argue, to speak of boundaries on the side of environment. When there is no action and certain molecules dispelled in the medium selectively cross the membrane, hardly any sense can be given to the idea of a stable structure that determines patterns of interaction. Let me reiterate: at this stage what is being enacted is the tenant.

But, once the possibility of action and interaction arises as result of the establishment of a stable tenant, there would be a growing need for stability and patterns on the side of the tenant's surroundings in order to make its actions efficient. I therefore propose that the second step of co-determination is C-niche (meta-metabolic) construction, resulting in a stable surrounding world divided into things, properties, regions, events, etc. While the M-niche is devoted to bringing forth a stable, bounded tenant, the $\mathrm{C}$-niche is devoted to delivering a stable domain for the tenant's actions.

Hence, the C-niche is conditioned by the tenant's sensorimotor capacities in the way already described. This means that the $\mathrm{C}$-niche is indirectly specified by the earlier M-niche, since the shape of the C-niche is determined by such and such features of the closed tenant. Note, however, that the conditions setting up the C-niche do not delineate the tenant, as this job is already done; they solely delineate certain patterns in its surroundings. This means that with respect to the $\mathrm{C}$-niche the tenant is open while the C-niche is internally closed. Hence:

30. In the second step of co-determination, C-niche construction produces a certain bounded environment (i.e., a certain $\mathrm{C}$-niche thought of as a product). The $\mathrm{C}$ niche is internally closed while its tenant is open.

Perhaps the idea of the tenant's openness to its C-niche does justice to the paradigms of extended mind and cognitive integration mentioned earlier. Note also that this openness-closedness structure manifests itself clearly from the first-person or phenomenological perspective. Time Crane gives a fitting formulation of it when he writes that "reflection on what it is like to have an experience does not reveal properties of experiences themselves, but only of their objects" (Crane 2006: p. 128). This phenomenon is familiar in the field of philosophy of perception as the transparency of experience. As simple as it is-the world seems to simply be there, present to me in a certain way, in a certain guise, by means of certain surfaces while my senses are merely transparent windows onto it (meaning-I am closed as an organism but I am fundamentally open to the world as a cognizer). There is a certain genuine experience of passivity in being presented with the world. Enactivism is right in stressing that this passivity is not constitutive of cognition, but it cannot ignore it either. Within the setup being proposed here, we can reintroduce the said passivity as a relatively stable product of C-niche construction, thus a product of a certain activity.

Now, this is the place where the real battle over the plausibility of introducing the cognitive niche takes place. Someone may argue that there is no need to postulate $\mathrm{C}$-niches as distinct from M-niches because the latter are perfectly sufficient. Firstly, it might be pointed out that distinguishing between metabolism and meta-metabolism is at odds with enactivism due to the fact that both of them are in the end realizations of a creature's autonomy. Therefore, the argument continues, the lived world of rela- 
tively stable things, processes and the like comes about on the basis of the history of interactions determined by autonomy, and there is no need for introducing cognitive niches as different from metabolic niches.

I shall not address the distinction between metabolism and meta-metabolism itself. In accordance with the working characterizations provided earlier, these two domains are different insofar as the term "metabolism" is restricted to patterns of chemical reactions delivering energy and thereby producing the organism, while the label "metametabolism" is used to refer to physical changes in the surroundings brought about by the organism's actions as a whole. However, taking into account that, indeed, both are realizations of a creature's autonomy, if metabolism is understood more broadly, then perhaps it could accommodate what van Duijn et al. (2006) classify as meta-metabolic. In my view, it is pointless to spill much ink over definitions as such.

Yet, another thing stands out as crucial in this context, namely that the distinction between metabolism and meta-metabolism must not be approached in separation from the issue of productivity, clearly singled out in $\S \S 4-5$. In this context, let us focus on the appeal enactivists make to history: what is so special about the history of interactions? My point is that there is nothing special: history is just a history; temporal processes are just processes; there is no creating power in the flow of time alone. These temporal processes must produce something. And this condition is non-trivial due to the already mentioned distinction between the act and the product: they are characterized by different features and there is no a priori necessity for all acts to result in products. Therefore, the bare fact that there are interactions does not mean that something is brought forth by them.

A proponent of representationalism might come up with the idea that over the course of evolution organisms acquire an ability to produce certain models of external reality out of the firings of neurons (e.g. see Fitch 2008). And it is not the case that action is neglected there; on the contrary, the ability to act within changing environments and to integrate different stimuli plays a crucial role in this representationalist story, as we can find out e.g. by studying a book by Burge (2010) or the recent, comprehensive study by Feinberg and Mallatt (2016) (see also Millikan 2006; Godfrey-Smith 2016b). Hence, we cannot hail enactivism just for the fact that it highlights the significance of action, because representationalism can do exactly the same thing.

Therefore, enactivism needs a different account of what is produced by the history of interactions. However, it must not be solely about the production of organisms or cognizers, thus a process of making the organism a bounded and internally coordinated unity. My argumentation in favor of the C-niche is thus based on the assumption that there is no a priori link between patterns of coordination "inside" the organism and patterns of the organism's interactions resulting in a relatively stable layout of the world which, in turn, determines and facilitates further interactions. Organisms might have thrived in a medium consisting of a flux lacking any patterns, yet they likely would not have been able to develop much. Evolution needed to find a way to conserve certain patterns, not only on the side of the organism, but also on the side of the world which (let us remember that VTR's abandonment of pre-givenness is assumed here) lacks any such patterns in itself. And this is where the C-niche comes in, being a product of certain actions undertaken by cognizers, yet not an internal construction, e.g. made up of neural firings; it is out there, as it were. 
Hence, it is not clear why the history of interaction or coupling alone is supposed to result in anything, but if this coupling is C-niche construction, then the appeal to history becomes plausible: this is the history inscribed, so to speak, in the structure of C-niches, just like the history of states is, in a sense, inscribed in institutions such as parliaments, supreme courts and the like. It seems likely that, as in the case of birds building nests, over the course of their ontogenesis and of evolution as a whole, cognizers, including the said birds qua cognizers, seek a conservation of their cognitive efforts and achievements; they seek relatively stable structures to achieve this aim. And seeking conservation is a well recognized phenomenon when it comes to evolution at large (e.g., see Kováč 2000; when it comes to cognition and conservation as recognized from a more general standpoint of philosophy of physics and philosophy of biology, see Kirchhoff 2016). ${ }^{19}$

So, the point is that organisms construct their C-niches as relatively stable structures conserving their cognitive "achievements". Clark (2008) and Sterelny (2010) have very similar ideas, however, in their view the $\mathrm{C}$-niche would be a product of rearranging the pre-given environment, while in my view-which is supposed to do justice to the original idea of VTR - the C-niche is about bringing forth an environment. For example, as a result of the first eyespots coming into being (which likely happened independently in many species), a certain lived world was brought forth because a certain new connection between the organism and its surroundings was established; a connection which previously did not exist. Hence, something became enacted, in VTR's vocabulary. The way in which we see the world through our eyes, thus the vision-based part of our lived world, results from the maintenance and development of the C-niche established together with the first eyespots coming into being. ${ }^{20}$

Finally, it is clear from the example just given that distinguishing the initial two steps of co-determination: M-niche construction and then C-niche construction, is not the end of the story, as the newly created C-niche, thus a set of patterns of interactions, opens up new possibilities for the reconstruction of the M-niche, including new resources. Hence, reciprocally, the C-niche conditions further developments of the M-niche, and the M-niche subsequently conditions new developments of the C-

\footnotetext{
19 Seeking conservation is referred to by L. Kováč as the principle of ratchetting. As he writes, ratcheting "in evolution, in development, and in cognition fulfills the same essential function: it allows step-wise accumulation and meaningful application of knowledge and prevents its futile diminution or degradation by running the process backwards. Ratchets operate at many hierarchical levels, from molecules up to megasocieties" (Kováč 2000: p. 63).

20 The idea of the first eyespot is of course a theoretical fiction, yet is has an explanatory role. In reality such clear cut-offs can hardly be drawn. Another point is that actual eyespots probably had nothing to do with what we would prefer to call cognition, even in its minimal forms; maybe it was just a transmitter of energy. Nonetheless, the distinction between the M-niche and the C-niche gives us a theoretical tool to apprehend how on the basis of an M-niche established by the first eyespots coming into being a C-niche was constructed over the course of evolution.
} 
niche, and so on indefinitely. ${ }^{21}$ So, I agree with Menary who holds that "cognition does not have a spatial boundary that lies at the periphery of the brain, or even at the skin" (Menary 2007: p. 4), but this does not mean that cognition has no boundary whatsoever. If the boundaries of the C-niche can count as what Menary refers to as the boundaries of cognition, then my claim is that there are many such boundaries, depending on whatever present state of co-determination.

\section{The realism versus idealism controversy}

I announced at the beginning of this study that the idea of enactment allows us to gain a new perspective on the realism-idealism controversy. VTR hint at the possibility of such a reading in several places, yet employing different notions. They write:

The treatment of the world as pregiven and the organism as representing or adapting to it is a dualism. The extreme opposite of dualism is a monism. We are not proposing monism; enaction is specifically designed to be a middle way between dualism and monism (ibid.: p. 202)

The C-niche is thought of as a middle ground between a pre-given, ready-made world hedged from the ready-made subject at the one extreme, and the idea of the self and the world being totally dissolved in each other, thus indistinguishable, at the other extreme. In this context it is worth noting that at the very beginning of their book VTR refer favorably to Merleau-Ponty's endeavor, saying that he recognized "a space between self and world, between the inner and the outer. This space was not a gulf or divide; it embraced the distinction between self and world, and yet provided the continuity between them" (ibid.: p. 3). So, the C-niche is intended to do justice to VTR's (and Merleau-Ponty's) conviction that the known shape of the world depends on the way it is cognized by such and such senses and intellectual capacities, while at the same time doing equal justice to the conviction that there is a reality under our feet and that we do not live within the projections of our minds.

In other words, if the lived world is a kind of niche, and if the internal boundary of this niche counts as the surface of the lived world, then the conception of cognition as niche construction entails nothing short of the claim that the lived world has no surface unless it is cognized. Someone might rapidly protest against this seemingly idealistic position, however, it does not mean that the base of the niche does not exist. The somewhat Kantian point is that we never have access to the base itself but only as far as it constitutes the medium of a niche. ${ }^{22}$

\footnotetext{
21 Hence, the C-niche emerged from the initial specification yielded by the M-niche and gave rise to a domain whose decoupling from metabolism, to use Moreno's et al (1997) term, would increase, resulting in human C-niches, decoupled to such a degree that their tenants would be prone to believe in the illusion that their cognitive niches are essentially distinct from the biological realm. Here we can see that the distinction enables us to understand how these two domains - the cognitive and the strictly biological—differ, and even why it is that people sometimes believe them to be essentially distinct, while at the same time we have developed tools to recognize the cognitive as emerging from the biological, thus to see continuity.

22 This point hints at a crucial issue called "fundamental circularity" by VTR, namely since we can have access to the base only via a certain $\mathrm{C}$-niche, this applies also to science and to this very ontological project: we investigate niches from the perspective of our human $\mathrm{C}$-niches.
} 
Finally, this issue also has to do with the question of directness. Usually, directness means at least two things ${ }^{23}$ : that there is no mediating entity between the cognizer and the perceived thing, as e.g., a sense-datum thought of as a separate mental object; or that knowledge grounded in perception is non-inferential, meaning that there is no mediating reasoning or computation. So, when I see a chair, it would be inadequate, according to proponents of direct perception in the latter sense, to say that my cognitive system as a whole, based on more or less sparse data, "comes to the conclusion" that I see a chair. Instead, e.g., in step with the claims made e.g., by Gibson (1979), it should rather be said that the chair is present to me already as an organized whole within my optic array.

Let me then point out that by directness here I mean lack of a mediating entity, leaving the other sense for another occasion. ${ }^{24}$ Now, theoretically there is always a gap between any two disconnected boundaries, even if it is not observable. And, insofar as physical space is at stake, the gap is always filled with some stuff. Hence, if perception is grounded in abutting, it cannot be deemed direct when approached by means of the proposed terminology. Meanwhile, even if our access to the niche base is possible only to the extent to which the latter constitutes the niche's medium, this access is still direct due to the tenant-niche connection. Hence, interestingly enough, the notion of niche construction conceived of as setting up connections articulates the idea of directness. And since directness is widely stressed by those who call themselves realists in the area of philosophy of perception, instead of speaking of the "idealistic underpinning" of VTR, as Pascal and O'Regan (2008) do, one might just as well speak of a "realistic underpinning."

The point that I would like to make, however, is that the notion of enactment thought of as niche construction goes beyond the Cartesian distinction between idealism, positing a pre-given subject, and realism, positing a pre-given world; it paves the way for thinking about cognition as having an impact or being productive, yet precisely without this dichotomy. This fact makes enactment potentially interesting also for those who do not necessarily enlist themselves for the enactivism movement proper.

\section{Further discussion and closing remarks}

It is worth noting that the proposed approach to cognition as a productive activity is in step with a broader movement called complexity science, spanning such a wide range of fields as thermodynamics, the origins of life, and the origins of cognition and society, devoted to explaining the mechanisms responsible for the spontaneous emergence of complexity in nature (see e.g., Kauffman 1993; Holland 1996). On that view, the very existence of material things in the Cartesian sense, thus of res extensa, as well as the

\footnotetext{
23 I would like to thank an anonymous reviewer for reminding me of that distinction.

24 Proponents of direct perception usually call themselves direct realists and put stress upon the claim that perceived things are fully mind-independent. This thesis can hardly come to terms with the idea of enactment. So, while enactivism can adhere to the abandonment of mediating entities, it can hardly accompany the direct realist in denying the occurrence of a mediating activity of some sort. The other thing, however, is whether enactment understood here as setting up boundaries of things, can be defined as reasoning or computation. The issue is quite complex and certainly merits a separate discussion.
} 
very existence of life and minded creatures was possible due to the fact that matter exhibits a "tendency" to establish more and more complex structures, such as organic compounds, cells, multicellular clusters, etc. The groundbreaking work in this field has been done by Ilya Prigogine, who was the first to describe so-called dissipative structures (see Prigogine 1997 for a more general overview). Hence, the emergence of niches, including $\mathrm{C}$-niches, is part of that story, too. It is certainly a broader topic requiring separate discussion, yet I consider my proposal as a special subchapter of that interdisciplinary effort, perhaps marginal from the properly scientific point of view, and perhaps even controversial from the uncompromised realistic perspective held by most scholars in this field. Nonetheless, what I have tried to pursue here can be described as making some introductory claims about how complexity and stability emerge in the peculiar domain of cognition or rather in-between the cognizing creature and its environment. In other words, how relatively stable structures come about not in the physical world proper (recall Lewontion's words quoted above) but in the lived world.

Now, complexity arises from "sociality" in the broadest possible sense, meaning that complex structures can emerge "when previously independent entities or events interact or are otherwise correlated" (Juarrero 2015: p. 514). One might argue that the proposed approach to enactment neglects this "sociality" and insist that the world is never enacted by one creature alone, closed in a bubble. One of the strongest antiCartesian points in the enactive paradigm is, admittedly, its abandonment of the notion of a solitary subject who is confined solely within her own ideas, impressions or sensedata. The breakthrough was perhaps best spelled out by the concept of participatory sense-making set forth by De Jaegher and Di Paolo (2007). But is it true that the niche approach neglects participation of more than one subject in the process of enactment, thus in the process of establishing complexity in the lived world? Indeed, the simplified model presented above starts from a single organism and its niche, but this rendering is not intended to suggest that there cannot be genuine participatory sense-making. Let me put it this way: if we say that complexity arises as result of "previously independent" creatures becoming "correlated," then any ontological theory must start from a notion capturing the initial state of "independence," as Juarrero (2015) dubs it, and then introduce a notion capturing "correlation," and finally a notion referring to the product of correlation. This is why I started from the perspective of a single organism/cognizer. Note however, that insofar as cognizers are open to their $\mathrm{C}$-niches (and the very purpose of $\mathrm{C}$-niche construction is the establishment of a stable environment by imposing a certain set of boundaries on the surrounding material), there is no a priori reason to deny the possibility of cognizers setting up connections with one another, setting the mentioned boundaries together and thereby establishing shared $\mathrm{C}$-niches. On the contrary, I believe that this is what actually happens and I think that the ontological model being set forth here is quite promising when it comes to our understanding of how deep and engaging the collaboration at stake actually is. Participatory C-niche construction is, however, a subject for another paper.

Open Access This article is distributed under the terms of the Creative Commons Attribution 4.0 International License (http://creativecommons.org/licenses/by/4.0/), which permits unrestricted use, distribution, 
and reproduction in any medium, provided you give appropriate credit to the original author(s) and the source, provide a link to the Creative Commons license, and indicate if changes were made.

\section{References}

Abrams, M. (2009). What determines biological fitness? The problem of the reference environment. Synthese, 166(1), 21-40.

Aizawa, K. (2015). Cognition and behavior. Synthese. https://doi.org/10.1007/s11229-014-0645-5.

Akagi, M. (2017). Rethinking the problem of cognition. Synthese. https://doi.org/10.1007/s11229-0171383-2.

Allen, C. (2017). On (not) defining cognition. Synthese. https://doi.org/10.1007/s11229-017-1454-4.

Allen, C., Bekoff, M., \& Lauder, G. (Eds.). (1998). Nature's purposes. Analyses of function and design in biology. Cambridge, MA: MIT Press.

Barron, A. B., \& Kline, C. (2016). What insects can tell us about the origins of consciousness. PNAS, 113(18), 4900-4908.

Bertolotti, T., \& Magnani, L. (2017). Theoretical considerations on cognitive niche construction. Synthese, $194,4757-4779$.

Betti, A. (2016). Kazimierz Twardowski. In Zalta, E. (Ed.), The Stanford encyclopedia of philosophy (Summer 2016 Edition). https://plato.stanford.edu/archives/sum2016/entries/twardowski/.

Burge, T. (2010). The origins of objectivity. Oxford: Oxford University Press.

Casati, R., \& Varzi, A. (1999). Parts and places. The structures of spatial representation. Cambridge, MA: MIT Press.

Chemero, A. (2009). Radical embodied cognitive science. Cambridge, MA: The MIT Press.

Clark, A. (2008). Supersizing the mind: Embodiment, action, and cognitive extension. Oxford: Oxford University Press.

Clark, A., \& Chalmers, D. (1998). The extended mind. Analysis, 58, 10-23.

Crane, T. (2006). Is there a perceptual relation. In T. S. Gendler \& J. Hawthorne (Eds.), Perceptual experience (pp. 126-146). Oxford: Oxford University Press.

Cummins, F., \& De Jesus, P. (2016). The loneliness of the enactive cell: Towards a bio-enactive framework. Adaptive Behavior. https://doi.org/10.1177/1059712316644965.

De Jaegher, H., \& Di Paolo, E. (2007). Participatory sense-making: An enactive approach to social cognition. Phenomenology and the Cognitive Sciences, 6(4), 485-507.

De Jesus, P. (2015). Autopoietic enactivism, phenomenology and the deep continuity between life and mind. Phenomenology and the Cognitive Sciences, 15, 265-289.

Di Paolo, E. A. (2005). Autopoiesis, adaptivity, teleology, agency. Phenomenology and the Cognitive Sciences, 4(4), 429-452.

Di Paolo, E. A. (2009). Extended life. Topoi, 28, 9-21.

Di Primio, F., Müller, B. S., \& Lengeler, J. W. (2000). Minimal cognition in unicellular organisms. In J. A. Meyer, A. Berthoz, D. Floreano, H. L. Roitblat, \& S. W. Wilson (Eds.), SAB2000 proceedings, supplement (pp. 3-12). Honolulu: International Society for Adaptive Behavior.

Dretske, F. (1995). Naturalizing mind. Cambridge, MA: MIT Press.

Elton, Ch S. (1927). Animal ecology. New York: Macmillan.

Feinberg, T. E., \& Mallatt, J. M. (2016). The ancient origins of consciousness. How the brain created experience. Cambridge, MA: MIT Press.

Fitch, W. T. (2008). Nano-intentionality: A defense of intrinsic intentionality. Biology and Philosophy, 23, 157-177.

Gibson, J. J. (1979). The ecological approach to visual perception. Boston: Houghton Mifflin.

Godfrey-Smith, P. (1996). Complexity and the function of mind in nature. Cambridge: Cambridge University Press.

Godfrey-Smith, P. (2014). Philosophy of biology. Princeton: Princeton University Press.

Godfrey-Smith, P. (2016a). Other minds: The Octopus, the Sea, and the deep origins of consciousness. New York: Farrar, Straus and Giroux.

Godfrey-Smith, P. (2016b). Individuality, subjectivity, and minimal cognition. Biology and Philosophy, 31(6), 775-796.

Herskovits, A. (1986). Language and spatial cognition. An interdisciplinary study of the prepositions in english. Cambridge: Cambridge University Press. 
Holland, J. H. (1996). Hidden order: How adaptation builds complexity. New York: Basic Books.

Hutchinson, G. E. (1957). Concluding remarks. Cold Spring Harbor Symposia on Quantitative Biology, 22(2), 415-427.

Hutto, D., \& Myin, E. (2013). Radicalizing enactivism: Basic minds without content. Cambridge, MA: MIT Press.

Hutto, D., \& Myin, E., (forthcoming). Going radical. Accessible on-line. https://www.academia.edu/ 15763822/Going_Radical.

Johnson, M. (1990). The body in the mind: The bodily basis of meaning, imagination, and reason. Chicago: University of Chicago Press.

Johnston, M. (2006). Better than mere knowledge? The function of sensory awareness. In T. S. Gendler \& J. Hawthorne (Eds.), Perceptual experience (pp. 260-290). Oxford: Oxford University Press.

Juarrero, A. (2015). What does the closure of context-sensitive constraints mean for determinism, autonomy, self-determination, and agency? Progress in Biophysics and Molecular Biology, 119, 510-521.

Kauffman, S. A. (1993). The origins of order: Self-organization and selection in evolution. Oxford: Oxford University Press.

Kirchhoff, M. D. (2016). Autopoiesis, free energy, and the life-mind continuity thesis. Synthese. https:// doi.org/10.1007/s11229-016-1100-6.

Kleinschmidt, S. (Ed.). (2014a). Mereology and location. Oxford: Oxford University Press.

Kleinschmidt, S. (Ed.) (2014a). Introduction (pp. xiii-xxxiii).

Kováč, L. (2000). Fundamental principles of cognitive biology. Evolution and Cognition, 6(1), 52-71.

Lakoff, G. (1990). Women, fire and dangerous things: What categories reveal about the mind. Chicago: University of Chicago Press.

Laland, K. N., Odling-Smee, J., \& Feldman, M. W. (1999). Evolutionary consequences of niche construction and their implications for ecology. Proceedings of the National Academy of Sciences, 96, 10242-10247.

Laland, K. N., \& Sterelny, K. (2006). Seven reasons (not) to neglect niche construction. Evolution, 60, 1751-1762.

Leonard, H. S., \& Goodman, N. (1940). The calculus of individuals and its uses. Journal of Symbolic Logic, $5,45-55$.

Leśniewski, S. (1916/1992). Podstawy ogólnej teoryi mnogości I, Prace Polskiego Koła Naukowego w Moskwie, Sekcya matematyczno-przyrodnicza, Moscow; English version: Foundations of the general theory of sets I. In Leśniweski, S (ed.) Collected Works (pp. 129-173). Dordrecht: Kluwer.

Lewontin, R. (1983). The organism as the subject and object of evolution. Scientia, 118, 63-82.

Lewontin, R. (2000). The triple helix. Gene, organism, and environment. Cambridge, MA: Harvard University Press.

Llored, J.-P., \& Harré, R. (2014). Mereology of chemistry. In C. Calosi \& P. Graziani (Eds.), Mereology and the sciences (pp. 189-212). Dordrecht: Springer.

Lyon, P. (2005). The biogenic approach to cognition. Cognitive Processing, 7(1), 11-29.

Maturana, H., \& Varela, F. (1980). Autopoiesis and cognition. The realization of the living. Dordrecht: Kluwer.

Menary, R. (2007). Cognitive integration: Mind and cognition unbounded. Basingstoke: Palgrave Macmillan.

Menary, R. (Ed.). (2010). The extended mind. Cambridge, MA: MIT Press.

Millikan, R. (2006). Styles of rationality. In S. Hurley \& M. Nudds (Eds.), Rational animals? (pp. 117-126). Oxford: Oxford University Press.

Moreno, A., Umerez, J., \& Ibañez, J. (1997). Cognition and life. The autonomy of cognition. Brain and Cognition, 34, 107-129.

Noë, A. (2004). Action in perception. Cambridge, MA: MIT Press.

Noë, A. (2009). Out of our heads. Why you are not your brain, and other lessons from the biology of consciousness. New York: Hill and Wang.

O'Regan, S., \& Noë, A. (2001). A sensorimotor account of vision and visual consciousness. Behavioral and Brain Sciences, 24(5), 939-973.

Pascal, F. P., \& O’Regan, J. K. (2008). Commentary On Mossio and Taraborelli: Is the enactive approach really sensorimotor? Consciousness and Cognition, 17(4), 1341-1342.

Perzanowski, J. (1993). Locative ontology Parts I-III. Logic and Logical Philosophy, 1, 7-94.

Pinker, S. (2010). The cognitive niche: Coevolution of intelligence, sociality, and language. PNAS, 107(11), 8993-8999.

Popper, K. R. (1972). Objective knowledge. An evolutionary approach. Oxford: Oxford University Press. 
Prigogine, I. (1997). The end of certainty. Time, chaos, and the new laws of nature. New York: The Free Press.

Putnam, H. (1982). Why there isn't a ready-made world. Synthese, 51(2), 141-167.

Ramsey, W. M. (2007). Representation reconsidered. Cambridge: Cambridge University Press.

Rowlands, M. (1999). The body in mind: Understanding cognitive processes. Cambridge: Cambridge University Press.

Rowlands, M. (2009). Enactivism and the extended mind. Topoi, 28(1), 53-62.

Rowlands, M. (in press). Disclosing the World: Intentionality and 4E Cognition. In Newen, A., de Bruin L., \& Gallagher, S. (eds.), Oxford handbook of cognition: Embodied, embedded, enactive and extended. Oxford: Oxford University Press.

Ryan, P. A., Powers, S. T., \& Watson, R. A. (2016). Social niche construction and evolutionary transitions on individuality. Biology and Philosophy, 31(1), 59-79.

Ryle, G. (1949). The concept of mind. Chicago: University of Chicago Press.

Simons, P. M. (1987). Parts: A study in ontology. Oxford: Clarendon Press.

Smith, B. (1996). Mereotopology: A theory of parts and boundaries. Data \& Knowledge Engineering, 20, 287-303.

Smith, B., \& Varzi, A. (1999). The Niche. Noûs, 33(2), 214-238.

Smith, B., \& Varzi, A. (2000). Fiat and Bona Fide boundaries. Philosophy and Phenomenological Research, $60(2), 401-420$.

Smith, B., \& Varzi, A. (2001). Environmental metaphysics. In U. Meixner (Ed.), Metaphysics in the postmetaphysical age. Proceedings of the 22th international Wittgenstein Symposium (pp. 231-239). Vienna: Hölder-Pichler-Tempsky.

Sterelny, K. (2007). Social intelligence, human intelligence and niche construction. Philosophical Transactions of the Royal Society B, 362, 719-730.

Sterelny, K. (2010). Minds: Extended or Scaffolded? Phenomenology and the Cognitive Sciences, 9, $465-481$.

Stewart, J., Gapenne, O., \& Di Paolo, E. A. (Eds.). (2010). Enaction: Toward a new paradigm for cognitive science. Cambridge, MA: MIT Press.

Taraborelli, D., \& Mossio, M. (2008). On the relation between the enactive and the sensorimotor approach to perception. Consciousness and Cognition, 17(4), 1343-1344.

Thompson, E. (2007). Mind in life: Biology, phenomenology, and the sciences of mind. Cambridge, MA: Harvard University Press.

Thompson, E., \& Stapleteon, M. (2009). Making sense of sense-making: Reflections on enactive and extended mind theories. Topoi, 28(1), 23-30.

Tooby, J., \& DeVore, I. (1987). The reconstruction of hominid behavioral evolution through strategic modeling. In W. G. Kinzey (Ed.), Primate models of hominid behavior (pp. 183-237). Albany: Suny Press.

Twardowski, K. (1912/1999). O czynnościach i wytworach. Kilka uwag z pogranicza psychologii, gramatyki i logiki. In: Ksiega Pamiatkowa ku uczczeniu 250-tej rocznicy założenia Uniwersytetu lwowskiego przez króla Jana Kazimierza. Tom II. Lwów: Wydawnictwo Uniwersytetu Lwowskiego: 1-33. English version in: K. Twardowski, On actions, products and other topics in philosophy (pp. 103-132) (edited by J. Brandl and J. Wolenski). Amsterdam: Rodopi.

van Duijn, M., Keijzer, K., \& Franken, D. (2006). Principles of minimal cognition: Casting cognition as sensorimotor coordination. Adaptive Behavior, 14(2), 157-170.

Varela, F., Thompson, E., \& Rosch, E. (1991). The embodied mind: Cognitive science and human experience. Cambridge MA: MIT Press.

Varzi, A. (2007). Spatial reasoning and ontology: Parts, wholes, and locations. In M. Aiello, I. PrattHartmann, \& J. van Benthem (Eds.), Handbook of spatial logics (pp. 945-1038). Berlin: Springer.

Varzi, A. (2016). Mereology. In Zalta, E. (Ed.), The Stanford encyclopedia of philosophy (Winter 2016 Edition). https://plato.stanford.edu/archives/win2016/entries/mereology/.

Volkenburg \& Kubovy. (2001). Auditory and visual objects. Cognition, 80(1-2), 97-126.

von Uexküll, J. (1926). Theoretical biology. New York: Harcourt, Brace \& Co.

Vörös, S., Froese, T., \& Riegler, A. (2016). Epistemological odyssey: Introduction to special issue on the diversity of enactivism and neurophenomenology. Constructivist Foundations, 11(2), 189-204.

Wallach, E. (2016). Niche construction theory as an explanatory framework for human phenomena. Synthese, 193(8), 2595-2618. 
Weber, A., \& Varela, F. (2002). Life after Kant. Natural purposes and the autopoietic foundations of biological individuality. Phenomenology and the Cognitive Sciences, 1(2), 97-125.

Werner, K. (2015). Towards a PL-metaphysics of perception. In Search of the metaphysical roots of constructivism. Constructivist Foundations, 11(1), 148-157.

Werner, K. (2017). Coordination produces cognitive niches, not just experiences a semi-formal constructivist ontology based on von Foerster. Constructivist Foundations, 12(3), 292-299.

Wittgenstein, L. (1953). Philosophical investigations. Oxford: Blackwell. 